\title{
Brincadeiras de rua, convivência urbana e ecologia dos saberes
}

\author{
ÁLAMO PIMENTEL \\ Universidade Federal de Alagoas, Maceió, AL, Brasil
}

\section{RESUMO}

Este artigo resulta de um estudo sobre a contribuição das brincadeiras de rua para a geração de processos de convivência urbana e a diversificação de práticas e saberes inerentes às culturas populares que atravessam o cotidiano das cidades brasileiras. $\mathrm{O}$ texto desenvolve-se com uma análise de documentos feita com base nos relatórios apresentados por estudantes de pedagogia de uma instituição de ensino superior do estado da Bahia. Os relatórios descritivos analisados resultam de um projeto didático de observação dos pontos de vistas das crianças sobre a convivência urbana. A base teórica do trabalho busca inspiração nas epistemologias do Sul, conforme proposição de Boaventura de Sousa Santos (2008), sobretudo no que diz respeito à compreensão das ecologias dos saberes. Tomando como base os quadros sinóticos apresentados ao longo do texto, expõe-se uma visão panorâmica das brincadeiras de rua em diferentes bairros de Salvador e suas implicações para a sustentabilidade das culturas populares nos cenários urbanos contemporâneos.

PALAVRAS-CHAVE

educação; culturas populares; brincadeiras de rua; convivência e ecologia dos saberes. 


\title{
STREET GAMES, URBAN LIFE, AND THE ECOLOGY OF KNOWLEDGE
}

\begin{abstract}
This article is the result of a study that explores the contribution of street games to urban conviviality/life. The study further explored the diversification of knowledge and practices inherent in popular cultures that permeate everyday life in Brazilian cities. The text is developed from an analysis of descriptive reports that were submitted by students from the institute of superior education of the state of Bahia. These reports are a result of a didactic project that sought to observe urban life from the children's point of view. The theoretical premise of this study is based on Southern epistemologies, a proposal by Boaventura de Sousa Santos (2008) that emphasizes a comprehension based on an ecology of knowledge. The synoptic tables presented throughout the text offer a panoramic vision of street games in different neighborhoods throughout Salvador as it also explores what these games may reveal about the sustainability of popular cultures in contemporary urban settings.
\end{abstract}

\section{KEYWORDS}

education; popular cultures; street games; conviviality and ecology of knowledge.

\section{JUEGOS DE LA CALLE, CONVIVENCIA URBANA Y ECOLOGÍA DE LOS SABERES}

\section{RESUMEN}

Este artículo es el resultado de un estudio sobre la contribución de los juegos de la calle en la creación de procesos de convivencia urbana y en la diversificación de prácticas y saberes inherentes a las culturas populares que atraviesan lo cotidiano de las ciudades brasileñas. El texto se desarrolla a partir del análisis de documentos basados en los informes presentados por estudiantes de pedagogía de una institución de enseñanza superior del estado de Bahía. Los informes descriptivos analizados son el resultado de un proyecto didáctico de observación desde el punto de vista de los niños sobre la convivencia urbana. La base teórica del trabajo se inspira en las epistemologías del Sul según la propuesta de Boaventura de Sousa Santos (2008), sobre todo en lo referido a la comprensión de las ecologías de los saberes. A partir de los cuadros sinópticos presentados a lo largo del texto se expone una visión panorámica de los juegos de la calle en diferentes barrios de Salvador y sus implicaciones en la sustentabilidad de las culturas populares en los escenarios urbanos contemporáneos.

\section{PALABRAS CLAVE}

educación; culturas populares; juegos de la calle; convivencia y ecología de saberes. 


\section{INTRODUÇÃO}

A ocorrência de brincadeiras de rua nas cidades brasileiras pode contribuir para a compreensão das configurações das culturas populares por meio da convivência urbana e, ao mesmo tempo, da diversidade de saberes que circulam entre os participantes dessas brincadeiras.

Este artigo parte do pressuposto de que a partir das brincadeiras de rua é possível compreender os múltiplos significados da convivência urbana, bem como a multiplicidade de saberes que circulam entre as pessoas que direta ou indiretamente participam da brincadeira. A base empírica do trabalho foram relatórios dos grupos de observação constituídos por estudantes do curso de pedagogia de uma instituição pública de ensino superior localizada em Salvador, capital do estado da Bahia. Os grupos foram orientados a buscar compreender o ponto de vista das crianças sobre a convivência urbana a partir das brincadeiras de rua. Parte dos relatórios foi selecionada para a composição de uma base de dados sobre a qual se utilizou o recurso de uma análise de documentos conforme critérios que serão explicitados mais adiante. Foram utilizadas como elementos de análises as descrições feitas pelos grupos de observação e as citações diretas dos testemunhos de algumas crianças entrevistadas.

A orientação conceitual dos trabalhos partiu do pressuposto de que as brincadeiras de rua podem ser compreendidas como dinâmicas sociointeracionais, por meio das quais as pessoas criam expressões simbólicas para diferentes ações compartilhadas coletivamente. As inspirações das epistemologias do Sul (Meneses; Santos, 2010) contribuíram para que a base teórica do trabalho fosse buscar diferentes referências de composição das análises desenvolvidas, bem como destacasse as brincadeiras de rua como interfaces das culturas populares na capital baiana. Isso porque um dos fatores que contribui para a ocorrência das brincadeiras é a falta de acesso por parte de algumas crianças a espaços privativos de lazer e, ao mesmo tempo, a existência de redes sociais nas comunidades populares que possibilitam a improvisação dos espaços nos quais as brincadeiras ocorrem. Faz parte das culturas locais em algumas comunidades urbanas de Salvador a ampliação dos espaços de interação social, a partir dos processos de convivência extrafamiliares. A rua, por assim dizer, torna-se uma zona de confluência entre o público e o privado a partir da qual é possível reconhecer as formas como se posicionam certas expressões da cultura que no âmbito deste texto são assumidas como culturas populares.

\section{A BRINCADEIRA COMO ELEMENTO DE TRADUÇÃO INTERCULTURAL}

A escolha do termo brincadeira de rua levou em conta o uso corriqueiro da expressão, segundo as comunidades abordadas ao longo do projeto didático que deu origem às bases empíricas deste estudo. Para a maioria dos moradores das comunidades visitadas, sair para brincar na rua é um acontecimento que envolve pessoas das mais diferentes faixas etárias, em diversas situações de convívio social. 
Além das crianças que participam diretamente das brincadeiras, pessoas jovens e adultas acompanham de perto as atividades, para garantir a segurança dos brincantes.

Aqui, o uso da expressão tal qual o linguajar dos praticantes das brincadeiras cumpre ao mesmo tempo uma inscrição epistemológica e uma inscrição empírica. Do ponto de vista epistemológico, o que se propõe é o exercício de uma hermenêutica diatópica em que ciência e senso comum constituam diálogos capazes de produzir transformações recíprocas em suas ferramentas conceituais e seus procedimentos metodológicos. Segundo Boaventura de Sousa Santos (2004, p. 264), "a hermenêutica diatópica requer não apenas um tipo de conhecimento diferente, mas também um processo de criação de conhecimento". Isso implica uma tradução intercultural na qual o termo "brincadeira" supõe correspondências semânticas ${ }^{1}$ no que diz respeito tanto às culturas populares quanto às culturas acadêmicas que lidam com esse tema de investigação.

Contribuiu para o desenvolvimento teórico do trabalho de pesquisa feita sobre os jogos e brincadeiras do povo Kalapalo, etnia indígena da Terra Indígena do Xingu, assim como os estudos de Roger Caillois (1990). Segundo os autores de pesquisa com os povos do Alto Xingu, por meio de jogos e brincadeiras, as pessoas constroem de forma lúdica situações de convívio social em que interagem umas com as outras e com o meio envolvente (Franco Neto; Fernandes; Herrero; 2006). Importante lembrar as contribuições de Luís da Câmara Cascudo (1976) para o tema quando afirma que, apesar da distinção conceitual entre jogo e brincadeira, ambos são manifestações de culturas populares que expressam o sentido lúdico da vida em comum, dado o sentido pedagógico que é atribuído ao jogo e a pressuposição do uso do brinquedo para o reconhecimento da brincadeira.

Do ponto de vista cultural, o uso comum da expressão "brincadeira" refere-se a um amplo repertório de atividades no qual uma sociedade expressa de maneira lúdica suas múltiplas relações com saberes, práticas e processos de identificações intragrupais. Nessa perspectiva, adotou-se o termo "brincadeira" como dinâmica sociointeracional produtora de situações de convívio social.

Do ponto de vista empírico, as "brincadeiras de rua" indicam expressões das culturas populares que situam e orientam as reflexões feitas a partir das descrições organizadas pelos estudantes do curso de pedagogia ao longo de seus trabalhos de campo. As brincadeiras traduzem práticas populares de ocupação dos espaços públicos, expansão das relações domésticas e, sobretudo, construção de alternativas de lazer e entretenimento extrafamiliares. Parte-se do pressuposto de que essas práticas são marcadas por diversidades de saberes sociais que circulam amplamente segundo diferentes relações geracionais, de gênero, étnico-raciais e econômicas. Isso porque todas as brincadeiras de rua descritas foram localizadas em bairros periféricos da capital soteropolitana. Acrescente-se a isso que foram identificadas diferentes formas de participação na brincadeira e para a realização da brincadeira, segundo critérios

1 Ainda segundo Boaventura de Sousa Santos (2004), o sentido diatópico dos trabalhos interpretativos busca estabelecer correlações de significados entre pontos de vistas diferentes produzidos pela ciência e pelo senso comum. 
de faixa etária e gênero. No que diz respeito às questões étnico-raciais, a maioria dos bairros em que as observações foram feitas é de locais em que predominam populações afrodescendentes.

Em composição com a noção de brincadeira de rua, as noções de convivência urbana e ecologia dos saberes complementam a temática deste estudo. Partiu-se da compreensão de que a convivência urbana é resultante de um mosaico de diferentes culturas em que pesam fatores identitários tais como idade e gênero (Fernández-Martorell, 2009). Para essa autora, as diferentes formas de convívio na cidade possibilitam compreender os processos de invenção e transformação da vida social nos espaços urbanos a partir das interações sociais que lhes são subjacentes. Acrescento às contribuições de Mercedes Fernández-Martorell as dimensões étnico-raciais e de classe social como outras interfaces constitutivas dos processos de convivência urbana que aqui são apresentados, inspirado nas contribuições de Norbert Elias (1994) e Néstor Garcia Canclini (1982, 2005). A noção de ecologia dos saberes pressupõe que as diferentes formas de organização social produzem e são produzidas por diferentes expressões de saberes, e o reconhecimento dessa diversidade de saberes supõe o desafio epistemológico da construção de novos procedimentos de correlações sustentáveis na interação desses saberes com as práticas sociais que thes conferem movimento (Santos, 2008).

Nesse sentido, o objetivo principal deste trabalho é compreender as interfaces entre culturas populares (supondo que algumas formas de convivência urbana são expressas a partir de performances das culturas populares $)^{2}$ e ecologias dos saberes presentes nas brincadeiras de rua contemporâneas na cidade de Salvador. Foram consideradas como questões centrais para o desenvolvimento das reflexões: 1) Como é possível compreender as culturas populares com base nas brincadeiras de rua?; 2) Quais as principais características dos processos convivenciais do ponto de vista das crianças que praticam brincadeiras de rua na capital do estado da Bahia?; 3) Quais as configurações da ecologia dos saberes presente nas brincadeiras de rua?

A base metodológica deste estudo é a análise documental. Conforme mencionado na introdução deste trabalho, o projeto didático que deu origem às visitas de campo para o reconhecimento das brincadeiras de rua nos bairros de Salvador gerou um conjunto de catorze relatórios descritivos, nos quais constavam as brincadeiras relacionadas a diversos aspectos espaciais, sociais e culturais. Considerando que nem todas as brincadeiras descritas nos relatórios aconteciam nas ruas dos bairros, algumas aconteciam em playgrounds e quadras poliesportivas de condomínios fechados, optou-se por selecionar os relatórios que apresentavam descrições das brincadeiras de rua propriamente ditas. A partir daí, o número de relatórios foi reduzido para

2 Compreendo que as diferenças de idade e gênero contribuem significativamente para os processos de interação que produzem as formas simbólicas de convivência urbana, conforme supõe Mercedes Fernández-Martorell, mas, procuro incorporar as contribuições de Canclini (1982) quando este nos faz lembrar de que as culturas populares se constituem a partir de apropriações desiguais dos bens econômicos e culturais de uma nação ou etnia e que tais culturas podem estar localizadas no campo ou na cidade. 
dez, o que corresponde a dez ruas de dez bairros diferentes da capital baiana, como veremos a seguir.

O conjunto de textos composto para as análises oferece dados que sugerem conexões entre o tema e os problemas do estudo mencionados anteriormente, daí o reconhecimento de que a análise de documentos possibilita "formular explicações plausíveis, produzir uma interpretação coerente, e realizar uma reconstrução de um aspecto qualquer de uma dada sociedade" (Cellard, 2008, p. 304). Dado o excesso de detalhes descritivos e diferenças de perspectiva de abordagem dos cenários do trabalho de campo, optou-se pela sistematização geral dos dados a partir do critério do resumo de detalhes, que implica buscar representações amplas de processos sociais a partir de significados elementares que traduzam aquilo que foi visto e descrito (Becker, 2009, p. 101). Tais significados compõem alguns quadros sinóticos nos quais se procura apresentar panoramas gerais das imbricações entre as brincadeiras de rua, o convívio urbano e as ecologias dos saberes. Ainda segundo sugestão de Howard Becker, a composição dos quadros possibilitou, em termos gerais, Análises de Espaços de Propriedades (AEP) (Becker, 2007, p. 219), dada a complexidade dos elementos e a multiplicidade de dimensões exploradas para a configuração dos processos convivenciais e suas conexões com a ecologia dos saberes.

Inicialmente, merece especial atenção o fato de que as brincadeiras de rua ocorrem graças à capacidade de mobilização de redes sociais nas comunidades, que operam as condições necessárias para que as crianças saiam às ruas em busca de diversão. Essas redes estão circunscritas a cenários urbanos carregados de configurações bastante específicas e, em certa medida, marcados por múltiplas referências de sociabilidade.

\section{CENÁRIOS URBANOS DAS BRINCADEIRAS DE RUA E SUAS REDES DE CONVÍVIO SOCIAL}

As ruas em que os trabalhos foram desenvolvidos ficam localizadas em áreas fora do centro da cidade, a grande maioria em bairros distantes e com a predominância de pessoas da classe média e pobres. A única exceção é o Dique do Tororó, local que foi especificamente planejado para servir de espaço de lazer para a população soteropolitana. ${ }^{3}$ Além de estarem situadas em bairros periféricos, essas ruas apresentam diferentes condições de ocupação. Identificam-se espaços improvisados e espaços planejados para a realização das brincadeiras. Compreendem-se por espaços improvisados aqueles que passam por intervenção dos participantes momentos antes da realização das brincadeiras (são pequenos espaços recuados, próximos ao meio fio das calçadas, ou qualquer área que ofereça proteção do trânsito de automóveis no local). Compreendem-se por espaços planejados aqueles que

3 Segundo Pedro de Almeida Vasconcelos (2002), o Parque do Dique do Tororó foi inaugurado no ano de 1998 como parte do processo de metropolização da capital baiana. O autor é responsável por um dos mais amplos estudos sobre as transformações e permanências no espaço urbano de Salvador entre 1549 e 1999. 
foram criados por ações dos poderes públicos, com o objetivo específico de oferecer condições de lazer para as situações de convívio urbano (praças, parques e jardins espalhados pela cidade, sobretudo).

É importante destacar que o processo de ocupação dos espaços de rua envolve diferentes movimentos das redes de convívio social que configuram as situações de brincadeiras de ruas. Adota-se aqui o conceito de rede de dependências no qual, segundo Norbert Elias (1994, p. 22), as pessoas se ligam "a outras por laços invisíveis, sejam estes laços de trabalho e propriedade, sejam de instintos e afetos". Foram identificados pelo menos três configurações de laços sociais que constituem as redes de convívio: 1) as pessoas se reúnem por laços de parentesco; 2) foram identificados laços de vizinhança; 3) há também os laços de circunvizinhança, que ampliam espacialmente as relações de proximidade entre as pessoas. Neste último caso, trata-se da participação de crianças que vêm de outras ruas ou até mesmo de outros bairros e que são filhos ou filhas de pessoas próximas de alguns dos moradores das ruas em que ocorrem as brincadeiras. Os cenários urbanos e as redes de convívio social constituem as principais bases materiais e imateriais para a realização das brincadeiras.

O Quadro 1 apresenta, em termos gerais, essas principais configurações sociais das comunidades descritas. Colocam-se em destaque aspectos enfatizados anteriormente, conforme as características dos espaços físicos das brincadeiras e as características da formação dos vínculos sociais nos grupos observados e descritos. Tudo isso a título de conferir maior clareza quanto às formas de ocupação do espaço, os laços de interdependência que dão sustentabilidade aos processos de ocupação, bem como o uso do espaço durante a realização das brincadeiras.

$\mathrm{Na}$ configuração desse primeiro quadro sinótico, a primeira coluna da esquerda para a direita destaca o grupo de observação por ordem numérica. $\mathrm{O}$ critério de definição numérica do grupo foi aleatório. É importante destacar que os tópicos subsequentes de localização dos grupos por local de observação conferem outras referências de identificação do grupo, segundo as experiências descritas. Essa foi uma forma de estabelecer sequencialidades covariacionais ${ }^{4}$ entre os grupos no escopo geral do quadro. Em cada linha podem ser observados os aspectos qualitativos que constituem as múltiplas dimensões de cada grupo nele mesmo. Entre as linhas e as colunas, as sequências de aspectos qualitativos podem apresentar as covariações entre os grupos apresentados.

O destaque conferido aos tipos de brincadeiras que ocorrem nesses espaços revela inicialmente a circulação de práticas culturais que estão relacionadas a tradições muito antigas, como o esconde-esconde, e, ao mesmo tempo, a jogos inventados a partir do uso de recursos materiais tradicionais, como a bola de gude e a corda. A

4 Trata-se de sequências nas quais podem ser identificados traços qualitativos comuns e podem ser estabelecidas covariações entre os grupos. As covariações foram utilizadas por Boaventura de Sousa Santos como base para o reconhecimento das características entre o direito oficial e o direito do asfalto (Santos, 1980). Essas covariações referem-se ao movimento teórico-prático necessário para a localização diacrônica dos espaços de produção dos discursos e diferenciação de suas práticas no interior da sociedade. 
Quadro 1 - Panorama geral das brincadeiras de rua em Salvador

\begin{tabular}{|c|c|c|c|c|c|}
\hline $\begin{array}{c}\text { Grupo de } \\
\text { observação }\end{array}$ & $\begin{array}{l}\text { Nome } \\
\text { da rua }\end{array}$ & Bairro & $\begin{array}{l}\text { Configurações } \\
\text { das ocupações } \\
\text { espaço-tempo }\end{array}$ & $\begin{array}{c}\text { Tipo da } \\
\text { brincadeira } \\
\text { descrita }\end{array}$ & $\begin{array}{l}\text { Características } \\
\text { da formação } \\
\text { de vínculos do } \\
\text { grupo social }\end{array}$ \\
\hline Grupo I & $\begin{array}{l}\text { Avenida } \\
\text { Dorival } \\
\text { Caymmi }\end{array}$ & Itapoan & Improvisado & Esconde-esconde & $\begin{array}{l}\text { Parentesco e } \\
\text { vizinhança }\end{array}$ \\
\hline Grupo II & $\begin{array}{l}\text { Beco do } \\
\text { Cirilo }\end{array}$ & $\begin{array}{l}\text { Baixa de } \\
\text { Quintas }\end{array}$ & Planejado & Esconde-esconde & $\begin{array}{l}\text { Parentesco e } \\
\text { vizinhança }\end{array}$ \\
\hline Grupo III & $\begin{array}{l}\text { Não } \\
\text { Identificado }\end{array}$ & Pau Miúdo & Improvisado & Pular elástico & $\begin{array}{l}\text { Vizinhança e } \\
\text { circunvizinhança }\end{array}$ \\
\hline Grupo IV & $\begin{array}{l}\text { Rua José } \\
\text { Abade }\end{array}$ & Boca do Rio & Improvisado & Pular corda & $\begin{array}{l}\text { Vizinhança e } \\
\text { circunvizinhança }\end{array}$ \\
\hline Grupo V & $\begin{array}{l}\text { Dique do } \\
\text { Tororó }\end{array}$ & Tororó & Planejado & Pega-pega & Parentesco \\
\hline Grupo VI & $\begin{array}{l}\text { Não } \\
\text { Identificado }\end{array}$ & $\begin{array}{l}\text { São Gonçalo } \\
\text { do Retiro }\end{array}$ & Improvisado & Pega-pega & $\begin{array}{l}\text { Parentesco e } \\
\text { vizinhança }\end{array}$ \\
\hline Grupo VII & Quadra 2 & $\begin{array}{l}\text { Castelo } \\
\text { Branco }\end{array}$ & Planejado & $\begin{array}{l}\text { Jogo de } \\
\text { tampinhas }\end{array}$ & $\begin{array}{l}\text { Vizinhança e } \\
\text { circunvizinhança }\end{array}$ \\
\hline Grupo VIII & $\begin{array}{l}\text { Rua do } \\
\text { Progresso }\end{array}$ & Pau da Lima & Planejado & Jogo de gude & $\begin{array}{l}\text { Parentesco, } \\
\text { vizinhança e } \\
\text { circunvizinhança }\end{array}$ \\
\hline Grupo IX & $\begin{array}{l}\text { Rua Onze } \\
\text { de Maio }\end{array}$ & Ribeira & Improvisado & Cinco cortes & $\begin{array}{l}\text { Vizinhança e } \\
\text { parentesco }\end{array}$ \\
\hline Grupo X & $\begin{array}{l}\text { Rua Antero } \\
\text { de Brito }\end{array}$ & Macaúbas & Improvisado & Sete pedras & Vizinhança \\
\hline
\end{tabular}

Fonte: Banco de dados da pesquisa.

Elaboração do autor.

escolha do repertório de brincadeiras segue o ritmo cotidiano das relações entre os participantes. Além do destaque para os espaços que são utilizados para brincar, há um amplo espectro de formas de ocupação do tempo livre que os brincantes adotam quando se reúnem nas brincadeiras.

Para a maioria dos grupos, a hora de brincar é definida pela combinação de três regras básicas: a negociação com a família do sair para brincar, a disponibilidade das 
crianças vizinhas para a brincadeira e a garantia da presença de olheiros para cuidarem das crianças. Essas regras básicas ocorrem nas ruas em que a brincadeira faz parte dos processos de convivência urbana. Nesses casos, as temporalidades da brincadeira são difusas e menos previsíveis, estão presentes na arte de fazer as brincadeiras no cotidiano da comunidade (Certeau, 2002). As regras de aproveitamento do tempo estão sempre presentes, embora a relação dialógica entre a permissão da família, a disponibilidade dos colegas e a presença dos olheiros seja cíclica e altamente variável de rua a rua, espaço a espaço, bairro a bairro, o que supõe, também, que "toda criança vai-se familiarizando com o 'tempo' como símbolo de uma instituição social cujo caráter coercitivo ela experimenta desde cedo" (Elias, 1998, p. 14).

No caso dos momentos de lazer em espaços especificamente planejados para esse fim, as escolhas são feitas de acordo com o planejamento familiar para a ocupação do tempo de estar em família. Isso não descarta a negociação da presença de crianças da vizinhança nos momentos de lazer em família.

$\mathrm{O}$ que se pode perceber é que as redes sociais que constituem as bases de sustentação das brincadeiras de rua produzem a emergência de outras referências temporais, espaciais e de produção de vínculos sociais. Essas referências diferenciam-se entre si quanto ao conteúdo, no entanto, ao assumirem as ruas dos bairros periféricos da capital baiana como cenários para seus desdobramentos, conferem correlações em suas formas enquanto culturas populares. Estar na rua ampliando e ocupando espaços públicos na convivência urbana é uma forma de praticar culturas populares por meio das brincadeiras de rua. $\mathrm{O}$ Quadro 1 apresenta esse panorama geral.

O Grupo $V$ destacou em sua descrição que as três meninas que brincavam de pega-pega no Dique do Tororó estavam na companhia da mãe. A observação foi feita em um dia de sábado (21 de julho de 2012). Segundo a conversa com as três meninas e com a mãe, nos finais de semana elas vão àquele local com a finalidade de "estar em contato com a natureza e não estudar". Uma das meninas, ainda segundo descrição do grupo de observação, afirmou que "o tempo de estudar é durante a semana, e o tempo do final de semana é para brincar". A mãe das garotas corroborou a informação e acrescentou que "aquele local era escolhido para que suas filhas tivessem maior contato com a natureza”. As regras de ocupação do espaço e do tempo, nesse caso, são mais planejadas e, ainda que não sejam cumpridas segundo um calendário rigoroso, correspondem às expectativas de um sistema público mais formal de dedicação ao lazer.

No caso das crianças que brincavam na Rua José Abade, a situação descrita é outra. O Grupo IV fez a observação durante uma tarde de sábado e descreveu que as crianças brincavam na rua por dois motivos: acontecia um churrasco em uma das casas da rua e isso possibilitava que vários adultos se posicionassem do lado de fora da residência para cuidar das crianças enquanto se divertiam; o outro fator que contribuiu para a realização das brincadeiras é que a rua não possui saída para veículos e, assim, oferecia mais segurança aos brincantes. Nesse caso específico, a negociação do tempo de brincar com a família e a disponibilidade dos colegas para a brincadeira, assim como o acontecimento do churrasco, produziram uma situação atípica na rua, que também foi descrita como uma rua com problemas de infraestrutura e local de ocorrência de crimes, segundo o grupo de observação. 
As situações de ocupação do espaço e tempo com as brincadeiras são variáveis e, ao mesmo tempo, recorrentes. Ou seja, apesar de serem imprevisíveis no que tange a uma definição rígida de horário e lugar, elas ocorrem quando as redes de convívio social operam as condições necessárias para que as brincadeiras aconteçam.

O fato de ocuparem espaços em que as relações de classe social são mais difusas e, sobretudo o fato de se posicionarem nas ruas, rompendo as fronteiras que separam séries incontáveis de distintivos sociais, contribui para que as culturas urbanas sejam compreendidas, por meio das brincadeiras de rua, como culturas populares em processo. Isso supõe que o reconhecimento dos processos simbólicos locais torna-se mais compreensível quanto mais reconhecemos as configurações do convívio social compartilhadas nas comunidades urbanas, conforme sugere Mercedes Fernández-Martorell (2009, p. 66). Ao mesmo tempo, é no meio da rua que a produção e a transformação de determinadas práticas culturais podem ser identificadas como populares pelos usos que lhes são atribuídos, conforme as relações de classe social configuradas no espaço urbano (Canclini, 1982, p. 47). As formas desiguais de acesso a espaços privativos de lazer conferem às crianças que ocupam as ruas com suas brincadeiras outras condições de significação do convívio social no espaço urbano.

\section{SIGNIFICAÇÕES DA CONVIVÊNCIA URBANA SOB A PERSPECTIVA DOS BRINCANTES}

As desigualdades sociais de acesso a espaços privativos de lazer produzem outras formas de processualização e significação da convivência urbana por meio das brincadeiras de rua. Além de irem às ruas à procura de diversão e liberdade, ${ }^{5}$ significações que apareceram em todos os grupos de observação, há inúmeras outras formas de significar a convivência urbana mediante as brincadeiras de rua.

Por meio das brincadeiras criam-se inúmeras estratégias para a lida com as situações de convívio social. Não é demais lembrar que, das tradições africanas que desembarcaram no Brasil, podemos encontrar nas mitologias dos orixás inúmeras referências para as práticas culturais que hoje fazem parte dos cotidianos de comunidades populares rurais e urbanas do Brasil.

Algumas dessas mitologias estão relacionadas aos Ibejis, irmãos gêmeos que vivem suas condições sempiternas de crianças e, por meio da brincadeira, traduzem as comunicações entre os orixás e os humanos. Aliás, uma das brincadeiras dos Ibejis descritas pela Mitologia dos orixás, de Reginaldo Prandi (2001), revela que os gêmeos resolveram enganar a morte (Icu). Para tal, utilizaram os recursos da

5 Para Huizinga (2010), o divertimento e a liberdade constituem a "essência" do jogo (ou da brincadeira). A concepção essencialista do jogo explorada pelo autor é em muitos aspectos questionável, no entanto, o destaque dado à diversão e à ação livre como atributos do jogo serviram de fonte de inspiração para a maioria dos estudos ocidentais sobre o tema. Talvez o melhor contraponto sobre a obra referida seja a proposição de uma sociologia dos jogos de Roger Caillois (1990). 
Quadro 2-Principais significados atribuídos à convivência pelas crianças

\begin{tabular}{|c|c|c|c|}
\hline Grupo de observação & Nome do bairro & Faixa etária & Significados atribuídos \\
\hline Grupo I & Itapoan & 4 a 6 anos & Diversão e liberdade \\
\hline Grupo II & Baixa de Quintas & 7 a 12 anos & $\begin{array}{l}\text { Diversão, liberdade e } \\
\text { ocupação do tempo }\end{array}$ \\
\hline Grupo III & Pau Miúdo & 6 a 14 anos & $\begin{array}{l}\text { Diversão, liberdade e fugir } \\
\text { da rotina doméstica }\end{array}$ \\
\hline Grupo IV & Boca do Rio & 6 a 12 anos & $\begin{array}{l}\text { Diversão, liberdade e } \\
\text { fruição da amizade }\end{array}$ \\
\hline Grupo V & Tororó & 8 a 13 anos & $\begin{array}{l}\text { Diversão, liberdade e } \\
\text { contato com a natureza }\end{array}$ \\
\hline Grupo VI & $\begin{array}{l}\text { São Gonçalo } \\
\text { do Retiro }\end{array}$ & 4 a 12 anos & $\begin{array}{l}\text { Diversão, liberdade e divisão } \\
\text { sexual de papéis sociais }\end{array}$ \\
\hline Grupo VII & Castelo Branco & 8 a 15 anos & Diversão e liberdade \\
\hline Grupo VIII & Pau da Lima & 9 e 12 anos & $\begin{array}{l}\text { Diversão, liberdade e } \\
\text { compensação da ausência } \\
\text { dos pais ou responsáveis }\end{array}$ \\
\hline Grupo IX & Ribeira & 1 a 15 anos & $\begin{array}{l}\text { Diversão, liberdade e } \\
\text { fruição da amizade }\end{array}$ \\
\hline Grupo X & Macaúbas & 6 a 12 anos & $\begin{array}{l}\text { Diversão, liberdade e } \\
\text { fruição da amizade }\end{array}$ \\
\hline
\end{tabular}

Fonte: Banco de dados da pesquisa.

Elaboração do autor.

música, da dança e do esconde-esconde. Icu, o espírito da morte, tinha espalhado armadilhas por toda a mata e estava capturando os humanos antes da hora determinada. Os Ibejis utilizaram o tambor mágico que ganharam de Iemanjá. Enquanto caminhavam pela mata, revezavam no toque de uma dança que encantou a morte. Icu não podia distinguir a semelhança entre os gêmeos. Eles utilizavam como estratégias esconder aquele que não toca ao longo do caminho, encantar a morte com a dança e despistá-la no momento de fazer o revezamento. Icu não conseguia parar de dançar e suplicou que a música fosse interrompida. Os Ibejis propuseram que a morte retirasse as armadilhas e deixasse o povo em paz. $\mathrm{O}$ acordo foi selado, e Icu desistiu de devorar os humanos. Os Ibejis e os diferentes mitos que evocam as tradições africanas nos revelam como as brincadeiras servem de amparo para diferentes situações de convívio social.

Os diferentes significados atribuídos à convivência urbana por meio das brincadeiras de rua encontram-se no Quadro 2. Para a elaboração desse quadro, foram destacados os grupos de observação, os bairros observados, a faixa etária das crianças e os principais significados atribuídos pelas crianças. É importante enfatizar 
que para a definição dos significados foram utilizadas informações diretas presentes nas entrevistas realizadas com as crianças, bem como informações indiretas presentes na descrição das cenas observadas.

A diversão e a liberdade, conforme anunciado anteriormente, aparecem como significados predominantes em todos os relatórios analisados. Aqui, o que se coloca em destaque é que a rua como espaço de convivência é um lugar para se divertir ou praticar a liberdade. Isso revela, do ponto de vista das crianças, um significado diametralmente oposto àquele que do ponto de vista dos adultos. Para Roberto DaMatta (1997), a rua é um "lugar do perigo". Além de ser um espaço de diversão e de gozo da liberdade, a rua pode ser um espaço de ocupação do tempo, conforme destaca o Grupo II. Nesse caso específico, as crianças afirmaram que vão brincar na rua "para não ficarem em casa sem fazer nada" (Grupo II) depois que cumprem os deveres escolares.

No caso do Grupo III, outro significado apresentado foi o da "fuga da rotina doméstica”. Observe-se que nesse caso o que pesa não é ocupar o tempo do ócio da vida doméstica, mas escapar às rotinas impostas pelos mais velhos. Por vezes, isso implica omissão do dever não cumprido com tarefas da escola ou mesmo da vida familiar. Segundo descrições feitas pelo Grupo III, as meninas que brincam de elástico "esquecem o tempo, ficam na rua até à noite e utilizam a brincadeira como um recurso para escapar da rotina doméstica”.

Outro significado que apareceu ao lado da diversão e da liberdade em três dos relatórios destaca a convivência urbana por meio das brincadeiras de rua como fruição da amizade. O Grupo IV indica que as crianças "só brincam na rua porque gostam dos amigos, pois, se não fosse isto, ficariam em casa na tevê ou no computador". No caso do Grupo IX, houve um destaque para o fato de que, entre as crianças, todas eram amigas (note-se que este é o único grupo em que aparece uma criança de um ano de idade, o que demonstra grande coesão social na rede de vizinhos da rua localizada no bairro da Ribeira). Foi revelado ainda que famílias que brigaram no passado retomaram seus laços mediante as relações entre os filhos com as brincadeiras de rua. No caso do Grupo X, foi revelado que "as crianças têm um bom relacionamento entre si, todas nasceram no Bairro de Macaúbas e pertencem a famílias que moram ali há muitos anos". A amizade é parte das tradições da rua, e por meio da brincadeira configuram-se os principais rituais de sociabilidade local.

Algumas famílias buscam nas brincadeiras de rua formas de oportunizar aos filhos maior contato com a natureza. Foi com base nessa compreensão que as crianças observadas no Dique do Tororó, pelo Grupo V, definiram suas experiências de convívio urbano por meio da natureza. No Grupo VI, a divisão sexual dos papéis sociais é que dá o tom na significação das brincadeiras. O grupo revelou que "ao longo da nossa convivência descobrimos que as meninas se reúnem para brincar de boneca, e os meninos, de bola". Nesse caso específico há uma nítida distinção entre as brincadeiras de meninas e as brincadeiras de meninos (conforme foi relatado também pelo Grupo III, Quadro 1, com relação à brincadeira de pular elástico).É importante ressaltar que a divisão sexual dos papéis sociais não é tão rígida, conforme relatou o grupo de observação, uma vez que as meninas eventualmente participam das brincadeiras dos meninos. 
Por fim, destaca-se como um dos significados singulares do conjunto geral dos grupos aquele no qual as crianças revelam que as brincadeiras de rua possibilitam a compensação da ausência dos pais ou responsáveis, conforme descreveu o Grupo VIII. Segundo esse grupo de observação, há várias crianças que entram nas brincadeiras de rua no momento em que os pais ou responsáveis estão trabalhando, ou resolvendo problemas pessoais fora dos domínios da comunidade. Os parentes e vizinhos oferecem auxílio na medida em que assumem posições de olheiros das crianças. Dois meninos abordados pelo grupo afirmaram que, quando a mãe sai para o trabalho, eles contam com as brincadeiras de rua e o apoio dos vizinhos para não ficarem sozinhos em casa. Esse é mais um significado de extrema importância para se compreender em profundidade a relevância das brincadeiras de rua na construção de situações de convívio urbano.

A diversidade de significações da convivência urbana a partir das brincadeiras de rua deixa entrever a inscrição de saberes sociais na vitalidade cognitiva (Santos, 2008), que põe em curso as culturas populares segundo o ponto de vista das crianças. Isso quer dizer que, além de encontrarmos uma multiplicidade de referências dos processos sociais envolvidos nas brincadeiras, elas também oferecem inúmeras possibilidades na produção de sentido para a vida em comum. As brincadeiras de rua nos colocam diante de várias referências nas éticas e estéticas do estar juntos, conforme sugere Michel Maffessoli (1984), e, ao mesmo tempo, geram um vasto campo de produção de saberes. É o social em pleno movimento de expansão ecológica de seus diversos processos cognitivos, como nos sugere Boaventura de Sousa Santos (2010).

Entre os povos do Alto Xingu, as crianças brincam de caçar, apesar de esses povos não serem guerreiros nem caçadores. Brincar de caçar é uma forma de pôr em curso uma série de saberes que estão presentes nas tradições desses povos. Segundo João Veridiano Franco Neto (2006), a brincadeira introduz elementos rituais em que o povo Kalapalo interage com a natureza como parte viva de seus contextos culturais. Em outra perspectiva, a pesquisadora Vanda Machado (2002) identificou que as crianças do Opô Afonjá, um dos maiores terreiros de Candomblé de Salvador, ocupam parte do tempo ocioso a brincarem de candomblé nas áreas exteriores aos barracões dos rituais religiosos. Para a autora, brincar de candomblé é parte do processo de formação das crianças dentro de uma das mais importantes tradições religiosas afro-brasileiras. Com isso podemos afirmar que, além de colocarem em curso processos de convivência pautados por diferentes significados, as brincadeiras de rua geram saberes que conferem sustentabilidade histórica a diferentes práticas culturais.

\section{CONFIGURAÇÕES DA ECOLOGIA DOS SABERES NAS BRINCADEIRAS DE RUA}

As brincadeiras de rua mobilizam diferentes práticas culturais e, ao mesmo tempo, evocam saberes para a composição de suas dinâmicas. Roger Caillois (1990) propôs que os jogos e as brincadeiras fossem compreendidos com base em diferentes princípios e, ao mesmo tempo, que fossem compreendidos a partir das maneiras 
de jogar. Quanto a este último aspecto, o reconhecimento dos comportamentos implicados na brincadeira definem as relações que os indivíduos estabelecem entre si. Para esse autor, os princípios do jogo são: Agon (marcado pela competição), Alea (destaca a sorte), Mimicry (enfatiza o simulacro) e Ilinx (destaca a vertigem). Quanto às maneiras de jogar, o autor sugere que sejam compreendidas a partir da exacerbação da alegria (Paidia) à imposição das regras (Ludus). As categorias do jogo são indissociáveis das maneiras de jogar e, em última análise, são deflagradoras de processos afetivo-cognitivos por meio dos quais a memória e a imaginação, de forma mais proeminente, mobilizam os indivíduos na construção das situações de convívio social mediante a brincadeira. É importante dizer que outras atividades cognitivas, como os raciocínios de cálculo, interpretação de situações vividas e construção de narrativas, também atuam nos circuitos de realização das brincadeiras.

O destaque para as contribuições de Roger Caillois deve-se ao fato de que, na perspectiva da ecologia dos saberes, segundo acepção de Boaventura de Sousa Santos, a diversidade epistemológica não está dissociada de uma diversidade ontológica e cultural (Santos, 2008, p. 143). Apesar da ênfase na sociologia do jogo, Roger Caillois contribuiu significativamente para a compreensão da brincadeira associada aos processos cotidianos como forma de compreender as diferenças entre as culturas e a importância do jogo na construção da experiência vivida (Caillois, 1990, p. 63). Ao mesmo tempo, a ecologia dos saberes, enriquecida pelas inspirações da sociologia do jogo, encontrará eco nas formulações da antropologia da convivência (Fernández-Martorell, 2009), quando essa autora reconhece que para apreender uma cultura é preciso compreender as formas por meio das quais as pessoas compartilham saberes. Em termos gerais, as configurações da ecologia dos saberes nas brincadeiras de rua apresentam, além dos significados socialmente compartilhados para as formas de convivência anteriormente analisados, habilidades e regras que tornam possível a participação dos brincantes nos processos convivenciais inerentes às brincadeiras e aos locais em que aquelas ocorrem.

As brincadeiras identificadas pelos grupos de observação mostram que as habilidades envolvidas e as regras necessárias para que aquelas sejam realizadas são constituídas a partir de diversas referências de saberes, experiências de vida e referências culturais presentes nos grupos observados, conforme mostra o Quadro 3.

Ao mesmo tempo em que foram observados grupos que brincam de esconde-esconde, brincadeira da qual se tem registro em povos da Antiguidade clássica (Cascudo, 1976) ou, conforme mencionado anteriormente, encontram-se referências entre povos africanos e os povos do Alto Xingu, ${ }^{6}$ foram identificadas brincadeiras improvisadas segundo as condições do momento. Segundo o Grupo IV, que fez observações à Rua José Abade, no Bairro da Boca do Rio, as crianças

6 O Uketimüho Konügü é uma versão do esconde-esconde dos povos Kalapalo. O jogo implica a caça dos participantes que ficam escondidos no mato, camuflados por lama. $\mathrm{O}$ caçador fica de bruços sobre a água, com a presença de outro participante, que o controla para que ele não espie os outros participantes enquanto estes procuram esconderijo. 
Quadro 3 - As brincadeiras segundo regras e habilidades implicadas

\begin{tabular}{|lll|}
\hline \multicolumn{1}{|c}{$\begin{array}{c}\text { Tipo de } \\
\text { brincadeira }\end{array}$} & \multicolumn{1}{c}{ Habilidades mais exigidas } & \multicolumn{1}{c|}{ Principais tipos de regras } \\
\hline Esconde-esconde & Habilidades motoras e comunicacionais & $\begin{array}{l}\text { Regras de liderança, } \\
\text { contagem e observação }\end{array}$ \\
Pular elástico & Habilidades motoras & $\begin{array}{l}\text { Regras de ritmo corporal, } \\
\text { resistência física e contagem }\end{array}$ \\
Pular corda & Habilidades motoras & $\begin{array}{l}\text { Regras de ritmo corporal, } \\
\text { resistência física e criatividade }\end{array}$ \\
Joga-pega & Habilidades motoras & $\begin{array}{l}\text { Regras de ritmo corporal, resistência } \\
\text { física, comunicação e contagem }\end{array}$ \\
Jogo de gude & Habilidades cognitivas & $\begin{array}{l}\text { Regras de contagem, comunicação } \\
\text { e interpretação situacional }\end{array}$ \\
Cinco cortes & Habilidades motoras e cognitivas & $\begin{array}{l}\text { Regras de contagem, comunicação } \\
\text { e interpretação situacional }\end{array}$ \\
Sete pedras & Habisica e interpretação situacional
\end{tabular}

Fonte: Banco de dados da pesquisa.

Elaboração do autor.

brincavam de pular corda com um velho pedaço de mangueira que foi doado por um parente de um dos participantes. Nesse caso, as modalidades do uso da corda para a brincadeira variavam de acordo com as proposições de uma das crianças, que mantinha o controle sobre o grupo e o pedaço de mangueira.

Todas as brincadeiras observadas envolvem habilidades motoras como característica fundamental. A maioria estaria incluída na categoria Ilinx, segundo a definição de Caillois, porque implicam atividades que exigem resistência física e vertigem. No caso do jogo de tampinhas e jogo de gude, podem ser identificados traços da categoria Agon e Alea, pois ambos implicam competição e, ao mesmo tempo, entrega à própria sorte.

O que interessa destacar é que as categorias alternam-se de forma cíclica, assim como as habilidades e regras presentes nas brincadeiras. À medida que estão em curso, as brincadeiras são geradoras de diferentes formas de praticar a vida social por meio das mais variadas referências existenciais e culturais que estão presentes nas ruas, com os grupos que constituem os processos convivenciais inerentes ao brincar. A partir daí, é possível compreender que as dinâmicas de interação entre os indivíduos são também dinâmicas de conversação entre diferentes expressões culturais, bem como construção de contextos sociais de vivências.

As brincadeiras de rua atualizam antigas tradições culturais ao tempo em que inventam novas tradições, a exemplo de brincadeiras como pular elástico, na 
qual as meninas (trata-se de uma brincadeira predominantemente feminina) improvisam elementos da ginástica rítmica para irem gradualmente desafiando umas às outras nas variações dos saltos sobre os fios do elástico. À medida que deflagram processos de convivência urbana, as brincadeiras de rua dão vazão a uma profusão de saberes por meio da qual a sociedade coloca em prática suas expressões culturais e, ao mesmo tempo, dá prosseguimento a sua história.

\section{CONCLUSÕES}

A ecologia dos saberes emergente dos processos convivenciais gerados pelas brincadeiras de rua não se restringe apenas aos aspectos práticos, afetivos e cognitivos referentes às próprias brincadeiras. Os diversos aspectos que atravessam a construção dos cenários urbanos e das redes sociais, assim como a proliferação de significados para a convivência pelas brincadeiras, geram diversidades epistemológicas, ontológicas e culturais.

Há saberes implicados na ocupação do espaço e na composição dos tempos de brincar. Em contrapartida, há aprendizagens do conviver inerentes aos desenvolvimentos das brincadeiras, o que supõe a construção de éticas e estéticas do estar juntos que prolongam a consolidação dos vínculos sociais, assim como produzem diferentes formas de solidariedade na ocupação dos locais em que as brincadeiras de rua ocorrem.

No que diz respeito à construção das brincadeiras, é importante destacar a processualização de práticas populares referentes a brincadeiras amplamente conhecidas em diferentes tradições, como brincadeiras inventadas pelos grupos locais. Ao mesmo tempo, as habilidades e regras que emergem dessas brincadeiras variam e conferem estatutos pedagógicos a estas, o que assegura sua permanência e circulações entre diferentes grupos, espaços e tempos sociais, ao mesmo tempo em que produzem diferenciações nos modos de ocupar os espaços públicos.

A expansão urbana das metrópoles brasileiras amplia a aprofunda as situações de conflito social nas formas de apropriação dos espaços públicos, sobretudo no que diz respeito à segregação dos espaços destinados à circulação social e ao lazer. As análises dos relatórios produzidos a partir da observação das brincadeiras de rua em bairros periféricos de Salvador apontam para múltiplas configurações geracionais, étnico-raciais, de classe social, de gênero, bem como dinâmicas de composições de redes sociais que se alteram conforme as circunstâncias locais que viabilizam a realização das brincadeiras. Os processos de convivência que emergem dessas redes também produzem formas coletivas de ocupação do espaço público e criam alternativas de socialização entre as pessoas.

Para alçar essas compreensões, fez-se necessário, por um lado, a exigência de uma abordagem interseccional dos processos sociais emergentes das brincadeiras de rua, a fim de compreendê-las como práticas culturais heterogêneas e dinamizadoras de fenômenos sociais mais amplos. Isso revela a importância de abordagens integrativas das múltiplas dimensões socioculturais envolvidas em tais processos, possibilitando a conversação com várias referências teóricas. Por outro lado, isso indica, também, a importância de se levar em conta as formas de apropriação dos 
espaços públicos a partir da atuação das crianças como agentes produtores de relações sociais as mais heterogêneas.

A rua, do ponto de vista dos adultos, é vista como lugar perigoso, pouco apropriado para o exercício da liberdade. No caso dos moradores dos bairros periféricos da capital baiana, as demandas por alternativas de entretenimento e socialização por parte das crianças mobilizam os adultos e produzem outras formas de ver, dizer e viver a rua. Os significados da rua, apontados pelas crianças, sugerem outras formas de compreensão desse lugar. Liberdade e diversão aparecem como significações que indicam outras éticas e estéticas da rua na convivência urbana.

Embora a ênfase teórica dos documentos tenha recorrido à ecologia dos saberes, conforme a proposição da sociologia das ausências e da sociologia das emergências, de Boaventura de Sousa Santos (2008), a sociologia dos jogos, de Roger Callois (1990), e a antropologia da convivência, de Mercedes Fernández-Martorell (2009), seus resultados apontam também para reflexões que vêm sendo desenvolvidas a partir das abordagens antropossociais de estudos com as crianças (Cohn, 2009; Corsaro, 2011; Pires, 2010), o que indica possibilidades de ampliação das bases teóricas desse trabalho em uma perspectiva interdisciplinar e, ao mesmo tempo, o investimento em novas investigações.

As crianças da periferia urbana de Salvador produzem outras relações com a rua e geram diferentes performances das redes sociais que são acionadas a partir das brincadeiras. Isso leva-nos a suspeitar que em outras regiões do país e do mundo contemporâneo onde ocorrem brincadeiras de rua, apesar da ostensiva privatização dos espaços de lazer, as formas de circulação de saberes e práticas sociais inerentes a essas brincadeiras também acionam outras expressões das culturas populares e, por que não dizer, dos processos de produção de conhecimento que não reduzem (tampouco essencializam) o brincar a uma particularidade da infância. As crianças, assim como os jovens e os adultos envolvidos nas circunstâncias espaço-temporais inerentes às ocorrências das brincadeiras, produzem múltiplas formas de conviver na cidade e com a cidade, daí derivam formas diferentes de ensinar e aprender geradoras de múltiplos processos educativos presentes na vida social.

É importante ressaltar ainda que os resultados aqui apresentados e as análises que sustentam as argumentações aqui realizadas foram produzidos a partir de uma experiência realizada em sala de aula, por meio do ensino da antropologia educacional. Além da evidente articulação teórica e prática que se fez presente no projeto didático precursor das experiências realizadas em campo, os relatórios produzidos constituíram-se em importante acervo documental, que alimentou as fontes de pesquisas constitutivas deste artigo. Isso realça a sala de aula como um rico campo para a consolidação dos vínculos entre práticas de ensino, extensão e pesquisa, dimensões intrínsecas da vida acadêmica. As experiências vividas pelos estudantes em sala de aula abriram outras possibilidades para a compreensão da atuação das crianças na produção social da convivência urbana.

Por meio das brincadeiras de rua, as culturas populares produzem, também, formas alternativas de permanência e transformação histórica, o que indica, para além da geração de processos convivenciais com suas diversidades de saberes, formas de resistência cultural que se deixam entrever nos pontos de vistas dos grupos 
sociais que, apesar da escalada dos conflitos na convivência urbana com as grandes metrópoles, encontram nas brincadeiras de rua outras formas de expansão de suas relações com os locais em que ocorrem.

\section{REFERÊNCIAS}

Becker, H. S. Segredos e truques da pesquisa. Rio de Janeiro: Jorge Zahar, 2007.

. Falando da sociedade. Rio de Janeiro: Jorge Zahar, 2009.

Caillois, R. Os jogos e os homens. Lisboa: Edições Cotovia, 1990.

Canclini, N. G. As culturas populares no capitalismo. São Paulo: Editora Brasiliense, 1982. . Consumidores e cidadãos. 3. ed. Rio de Janeiro: Editora UFRJ, 2005.

Cascudo, L. C. História dos nossos gestos: uma pesquisa mímica do Brasil. 3. ed. São Paulo: Edições Melhoramentos, 1976.

Cellard, A. A análise documental. In: Deslauriers, J.P.; Poupart, J. (Orgs.). A pesquisa qualitativa: enfoques epistemológicos e metodológicos. Petrópolis: Editora Vozes, 2008. p. 295-316.

Certeau, M. A invenção do cotidiano: artes de fazer. Petrópolis: Editora Vozes, 2002.

Сoнn, C. Antropologia da criança. Rio de Janeiro: Jorge Zahar, 2009.

Corsaro, W. A. A sociologia da infância. Porto Alegre: Artmed, 2011.

DAMatta, R. A casa E a rua: espaço, cidadania, mulher e morte no Brasil. 5. ed. Rio de Janeiro: Rocco, 1997.

Elias, N. A sociedade dos indivíduos. Rio de Janeiro: Jorge Zahar, 1994.

Sobre o tempo. Rio de Janeiro: Jorge Zahar, 1998.

Fernández-Martorell, M. Antropología de la convivencia: manifiesto de antropologia urbana. Madrid: Ediciones Cátedra, 2009.

Franco Neto, J. V.; Fernandes, U.; Herrero, M. Jogos e brincadeiras do povo Kalapalo. São Paulo: SESC, 2006.

Huizinga, J. Homo ludens. 7. ed. São Paulo: Editora Perspectiva, 2010.

Machado, V. Ilê Axé vivências e invenção pedagógica: as crianças do Opô Afonjá. Salvador: EDUFBA, 2002.

Maffessoli, M. A conquista do presente. Rio de Janeiro: Rocco, 1984.

Meneses, M. P.; Santos, B. S. Epistemologias do Sul. Coimbra: Almedina CES, 2010.

Pires, F. O que as crianças podem fazer pela antropologia? Horizontes Antropológicos, Porto Alegre: PPGAS, ano 16, n. 34, p. 137-157, 2010.

Prandi, R. Mitologia dos orixás. São Paulo: Cia das Letras, 2001.

SAntos, B. S. O discurso e o poder: ensaio sobre a sociologia da retórica jurídica. 2. ed. Coimbra: Boletim da Faculdade de Direito da Universidade de Coimbra, 1980. . Por uma concepção multicultural de Direitos Humanos. In: BALcı, C.A.(Org.). Direitos Humanos na sociedade cosmopolita. Rio de Janeiro: Renovar, 2004. p. 249-272. 
Santos, B. S. A gramática do tempo: para uma nova cultura política. 2. ed. São Paulo: Cortez Editora, 2008.

VAsconcelos, P. A. Salvador: transformações e permanências (1549-1999). Ilhéus: Editus, 2002.

\section{SOBRE O AUTOR}

Álamo Pimentel é doutor em educação pela Universidade Federal do Rio Grande do Sul (UFRGS). Professor da Universidade Federal de Alagoas (UFAL).

E-mail: alamopimentelmcz@gmail.com

Recebido em março de 2013 Aprovado em outubro de 2014 